\title{
CITARUM HARUM - INVESTIGASI LAPANGAN UNTUK MENGUKUR TINGKAT SEDIMENTASI PADA SUNGAI CITARUM
}

\author{
Vittorio Kurniawan, ST., M.Sc. ${ }^{1}$, Ir. Ni Luh Shinta Eka Setyarini, MT. ${ }^{2}$, dan \\ Dr. Widodo Kushartomo S.Si., M.Si. ${ }^{3}$, Anissa Noor Tajudin, ST., M.Sc. ${ }^{4}$, Arif Sandjaya, \\ ST., MT. ${ }^{5}$
}

\author{
${ }^{1}$ Program Studi Teknik Sipil, Universitas Tarumanagara \\ Email:vittoriokurniawan@gmail.com \\ ${ }^{2}$ Program Studi Teknik Sipil, Universitas Tarumanagara \\ Email: shintarachmat@yahoo.com \\ ${ }^{3}$ Program Studi Teknik Sipil, Universitas Tarumanagara \\ Email:widodokushartomo@untar.ac.id \\ ${ }^{4}$ Program Studi Teknik Sipil, Universitas Tarumanagara \\ Email: anissat@ft.untar.ac.id \\ ${ }^{5}$ Program Studi Teknik Sipil, Universitas Tarumanagara \\ Email: arifs@ft.untar.ac.id
}

\begin{abstract}
ABSTRAK
Sungai Citarum adalah sungai yang sangat strategis bagi masyarakat mengingat Sungai Citarum merupakan sungai yang menjadi sumber kehidupan bagi 35 juta jiwa masyarakat yaitu sumber air baku bagi penduduk DKI Jakarta, sumber air irigasi seluas 420.000 hektar di Jawa Barat, sumber listrik sebesar 1.900 MW bagi kawasan Jawa-Bali, dan rumah bagi 3 bendungan besar. Namun, Sungai Citarum tengah berada dalam masalah sedimentasi yang akan memperparah efek banjir dan memperpendek umur bendungan-bendungan yang ada.

Kegiatan investigasi lapangan di Sungai Citarum dilaksanakan pada Mei 2018. Kegiatan ini dilakukan di beberapa lokasi di sepanjang Sungai Citarum dari hulu sampai hilir pada sebanyak 5 titik. Pada lokasi-lokasi ini, survey hidrometri yang dilakukan adalah pengukuran kecepatan arus sungai dengan currentmeter dan pengukuran kadar sedimen layang dengan US DH-48. Kedua pengukuran tersebut dilakukan pada beberapa titik di satu penampang untuk mendapatkan rata-rata dari kecepatan aliran dan kadar sedimen layang.

Dengan menganalisis hasil pengamatan, dapat disimpulkan bahwa bahwa kadar sedimen layang cenderung lebih besar di daerah hilir daripada di daerah hulu. Hasil ini menyiratkan bahwa semakin banyak sedimen yang terdapat pada sungai di bagian hilir dibandingkan dengan di bagian hulu. Hal ini disebabkan oleh banyaknya sedimen yang berasal dari longsoran DAS Citarum. Semakin ke hilir, semakin banyak sedimen yang masuk ke dalam sistem Sungai Citarum. Fenomena ini konsisten dengan maraknya perubahan tata guna lahan dari hutan ke daerah industri atau permukiman yang memudahkan terjadinya longsoran sedimen dari DAS ke dalam tubuh sungai.
\end{abstract}

Kata kunci: Sungai Citarum; sedimentasi; erosi; hidrometri.

\section{PENDAHULUAN}

Sungai Citarum adalah sungai terbesar di Jawa Barat dan merupakan sungai dengan peran yang sangat strategis bagi masyarakat di sekitarnya. Sungai Citarum merupakan sungai yang menjadi sumber kehidupan bagi 35 juta jiwa masyarakat yaitu sumber air baku bagi penduduk DKI Jakarta, sumber air irigasi seluas 420.000 hektar di Jawa Barat, sumber listrik sebesar 1.900 MW bagi kawasan Jawa-Bali, dan rumah bagi 3 bendungan besar. Karena itu, kondisi Sungai Citarum harus dijaga agar manfaatnya dapat terjaga.

Salah satu masalah yang menghantui Sungai Citarum adalah masalah sedimentasi. Sedimentasi akan menyebabkan kenaikan dasar sungai dan/atau penyempitan lebar sungai yang akan memperparah banjir yang sudah ada. Selain itu, sedimen pada sungai akan masuk ke dalam bendungan-bendungan yang ada dan memperpendek masa layan dari bendungan-bendungan 
tersebut. Hal ini sudah disampaikan oleh Sutjiningsih (2012) dan dikonfirmasi dengan data yang bersumber dari PT Indonesia Power selaku pengelola bendungan seperti yang ditampilkan pada Tabel 1. Tabel tersebut menunjukkan bahwa bendungan Saguling sudah menerima 88 juta $\mathrm{m}^{3}$ dari tahun 1985 sampai 2007.

Tabel 1. Volume sedimen pada bendungan Saguling (PT Indonesia Power, Unit Bisnis Pembangkit Saguling, 2008)

\begin{tabular}{|c|c|c|c|c|c|c|c|}
\hline \multirow{3}{*}{ No } & \multirow{3}{*}{ Tahun } & \multirow{3}{*}{$\begin{array}{c}\text { Volume } \\
\text { Sedimen } \\
\left(\mathrm{m}^{3}\right)\end{array}$} & \multirow{3}{*}{$\begin{array}{c}\text { Erosi } \\
\text { Cacth- } \\
\text { ment } \\
(\mathrm{mm})\end{array}$} & \multicolumn{4}{|c|}{$\begin{array}{l}\text { Volume Sedimen } \\
\text { Berdasarkan fungsi }\end{array}$} \\
\hline & & & & \multicolumn{2}{|c|}{ Dead Storage } & \multicolumn{2}{|c|}{ Life Storage } \\
\hline & & & & Volume $\left(\mathrm{m}^{3}\right)$ & $\%$ & Volume $\left(\mathrm{m}^{3}\right)$ & $\%$ \\
\hline 1 & Planning of NEW JEC & 4.000 .000 & 2,10 & 167.689 .000 & & & \\
\hline 2 & Feb 1985 s/d Des 1987 & 5.390 .420 & 2,83 & 4.179 .522 & 78 & 1.210 .898 & 22 \\
\hline 3 & Des 1987 s/d Des 1988 & 1.583 .463 & 0,83 & 641.919 & 41 & 941.544 & 59 \\
\hline 4 & Des $1988 \mathrm{~s} / \mathrm{d}$ Des 1989 & 3.992 .651 & 2,10 & 2.346 .299 & 59 & 1.646 .352 & 41 \\
\hline 5 & Des $1989 \mathrm{~s} / \mathrm{d}$ Des 1990 & 3.269 .853 & 1,72 & 2.432 .498 & 74 & 837.355 & 26 \\
\hline 6 & Des 1990 s/d Des 1991 & 3.019 .621 & 1,59 & 2.029 .633 & 67 & 989.988 & 33 \\
\hline 7 & Des $1991 \mathrm{~s} / \mathrm{d}$ Des 1992 & 4.234 .036 & 2,22 & 1.577 .192 & 37 & 2.656 .844 & 63 \\
\hline 8 & Des 1992 s/d Des 1993 & 4.076 .992 & 2,14 & 3.023 .836 & 74 & 1.053 .156 & 26 \\
\hline 9 & Des 1993 s/d Des 1994 & 4.205 .095 & 2,21 & 6.286 .381 & 149 & -2.081 .286 & -49 \\
\hline 10 & Des 1994 s/d Des 1995 & 4.139 .966 & 2,17 & 3.919 .997 & 95 & 219.969 & 5 \\
\hline 11 & Des 1995 s/d Des 1996 & 4.226 .388 & 2,22 & 2.513 .414 & 59 & 1.712 .974 & 41 \\
\hline 12 & Des 1996 s/d Des 1997 & 4.035 .755 & 2,12 & 3.414 .373 & 85 & 621.382 & 15 \\
\hline 13 & Des 1997 s/d Des 1998 & 4.521 .803 & 2,37 & 2.763 .241 & 61 & 1.758 .562 & 39 \\
\hline 14 & Des 1998 s/d Des 1999 & 4.315 .593 & 2,27 & 3.772 .732 & 87 & 542.861 & 13 \\
\hline 15 & Des $1999 \mathrm{~s} / \mathrm{d}$ Des 2000 & 4.131 .027 & 2,17 & 1.892 .056 & 46 & 2.238 .971 & 54 \\
\hline 16 & Des 2000 s/d Des 2001 & 4.296 .268 & 2,26 & 1.256 .016 & 29 & 3.040 .252 & 71 \\
\hline 17 & Des $2001 \mathrm{~s} / \mathrm{d}$ Des 2002 & 4.197 .152 & 2,20 & 1.905 .720 & 45 & 2.291 .432 & 55 \\
\hline 18 & Des 2002 s/d Des 2003 & 4.195 .995 & 2,20 & 4.006 .942 & 95 & 189.053 & 5 \\
\hline 19 & Des 2003 s/d Des 2004 & 4.090 .927 & 2,15 & 3.080 .706 & 75 & 1.010 .221 & 25 \\
\hline 20 & Des 2002 s/d Des 2005 & 4.171 .461 & 2,01 & 3.785 .101 & 91 & 386.360 & 9 \\
\hline 21 & Des 2002 s/d Des 2006 & 4.235 .007 & 2,22 & 3.308 .338 & 78 & 928.669 & 22 \\
\hline 22 & Des 2002 s/d Des 2007 & 4.315 .404 & 2,23 & 3.339 .129 & 77 & 976.275 & 23 \\
\hline & Jumlah & 88.644 .877 & 2,10 & 61.475 .045 & 72 & 19.870 .307 & 28 \\
\hline
\end{tabular}

Publikasi dari Poerbandono (2006) menyebutkan bahwa laju ekspor sedimen pada Sungai Citarum telah meningkat sebanyak 2 kali lipat yaitu dari 1,18 juta ton pada tahun 1993 menjadi 2,15 juta ton pada tahun 2003. Hal ini diduga disebabkan oleh berubahnya tata guna lahan di Daerah Aliran Sungai (DAS) Citarum) dari perhutanan menjadi industri dan permukiman. 
Akibatnya, erosi lahan meningkat tajam dan tanah yang tergerus tersebut akan bergerak menuju sungai. Ilyas (2002) yang mengutip laporan Bank Dunia melaporkan bahwa pada tahun 1985 telah ada 1,9 juta hektar lahan kritis dengan tingkat laju erosi rata-rata 20-60 ton/ha/tahun. Angka ini jauh lebih besar daripada laju erosi rata-rata yang bisa ditoleransi yaitu 12,5 ton/ha/tahun (Arsyad, 1989) .

\section{METODOLOGI}

Kegiatan pengabdian kepada masyarakat ini dilaksanakan pada tanggal 15-17 Mei 2018. Kegiatan ini dilakukan di beberapa lokasi di sepanjang Sungai Citarum dari hulu sampai hilir seperti yang ditunjukkan oleh Gambar 1.

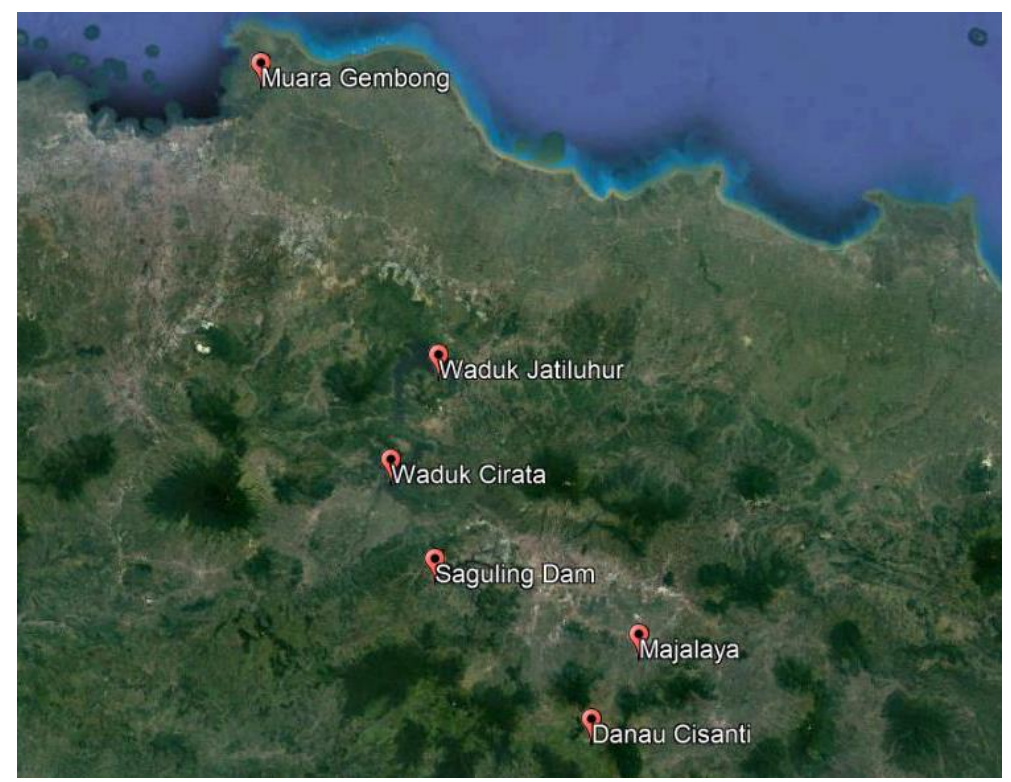

Gambar 1. Lokasi pengambilan sampel

Dalam rentang periode ini, pengukuran hidrometri untuk pemeriksaan sedimentasi dilakukan pada lokasi-lokasi berikut :

Tabel 2. Lokasi dan waktu pengambilan sampel hidrometri

\begin{tabular}{|c|c|c|c|c|c|c|c|}
\hline Lokasi & Tanggal & $\begin{array}{l}\text { Waktu } \\
\text { Mulai }\end{array}$ & $\begin{array}{l}\text { Waktu } \\
\text { Selesai }\end{array}$ & Cuaca & $\begin{array}{c}\text { Lebar } \\
\text { Sungai } \\
\text { (m) }\end{array}$ & $\begin{array}{l}\text { Koordinat } \\
\text { (UTM) }\end{array}$ & $\begin{array}{c}\text { Elevasi } \\
(+\mathbf{m})\end{array}$ \\
\hline Situ Cisanti & $15 / 05 / 2018$ & $10: 30$ & $10: 48$ & Cerah & 1,14 & $\begin{array}{l}48 \text { M } 0793721 \\
9202378\end{array}$ & 1588 \\
\hline Majalaya & $15 / 05 / 2018$ & $13: 50$ & $14: 32$ & Cerah & 6,22 & $\begin{array}{l}48 \text { M } 0804499 \\
9219819\end{array}$ & 692 \\
\hline $\begin{array}{l}\text { S. Citarum ke } \\
\text { Cirata }\end{array}$ & $16 / 05 / 2018$ & 12:00 & $12: 45$ & Cerah & 50,67 & $\begin{array}{lll}48 & \text { M } & 0756992 \\
9243128\end{array}$ & 240 \\
\hline $\begin{array}{l}\text { S. Citarum ke } \\
\text { Jatiluhur }\end{array}$ & $16 / 05 / 2018$ & $17: 34$ & 18:03 & Cerah & 55,13 & $\begin{array}{l}48 \text { M } 0759698 \\
9260874\end{array}$ & 121 \\
\hline $\begin{array}{l}\text { Muara } \\
\text { Gembong }\end{array}$ & $17 / 05 / 2018$ & $12: 20$ & $12: 50$ & Mendung & 67,72 & $\begin{array}{l}48 \text { M } 0732499 \\
9334683\end{array}$ & 12 \\
\hline
\end{tabular}


Acuan dalam melakukan pengukuran kecepatan aliran Sungai Citarum adalah SNI 3414-2008 Tata cara pengambilan contoh muatan sedimen melayang di sungai dengan cara integrasi kedalaman berdasarkan pembagian debit. Pada penelitian kali ini, kecepatan aliran diukur dengan menggunakan alat currentmeter dengan baling-baling tipe 1-51029.

Langkah-langkah dalam mengukur kecepatan aliran pada penelitian ini adalah :

1. Pilih lokasi yang hendak diukur kecepatannya.

2. Currentmeter dibenamkan ke dalam air selama 1 menit atau 60 detik.

3. Catat nilai dari jumlah putaran currentmeter sesuai dengan yang tertera pada recorder.

4. Pada satu lokasi/penampang, ukur kecepatan arus sebanyak 5 titik yaitu di tepi kiri, kiritengah, tengah, tengah-kanan, dan tepi kanan. Catat jumlah putaran currentmeter per menit pada setiap titik agar nilai kecepatan alirannya dapat dirata-ratakan.

5. Ulangi langkah 2-4 untuk lokasi-lokasi lainnya.

Suatu fungsi diperlukan untuk mengkonversi jumlah putaran currentmeter per menit ke kecepatan aliran dalam meter/detik. Rumus yang dipakai adalah :
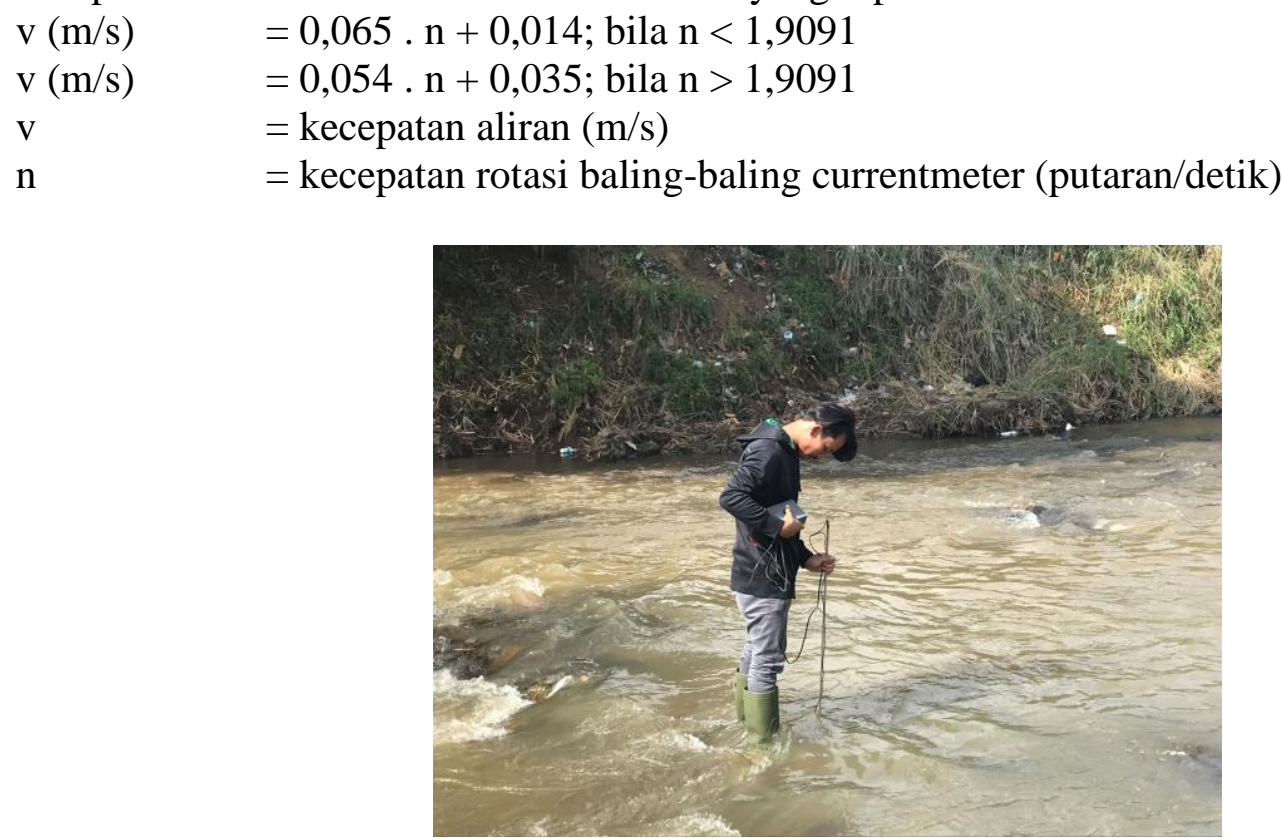

Gambar 2. Contoh pengukuran kecepatan aliran di Majalaya

Acuan dalam melakukan pengukuran kadar sedimen layang dari aliran Sungai Citarum adalah SNI 3414-2008 Tata cara pengambilan contoh muatan sedimen melayang di sungai dengan cara integrasi kedalaman berdasarkan pembagian debit. SNI ini menguraikan alat-alat yang diperlukan untuk mengukur kecepatan aliran beserta dengan cara-caranya. Alat US DH-48 digunakan untuk menangkap sedimen layang yang terdapat pada sungai.

Langkah-langkah dalam mengukur kadar sedimen layang pada penelitian ini adalah :

1. Pilih lokasi yang akan diukur kadar sedimen layangnya.

2. US DH-48 ditenggalamkan ke dalam air sampai botolnya terisi penuh.

3. Keluarkan botol sampel dari US DH-48 dan pindahkan airnya ke botol lain yang sudah disiapkan

4. Beri label pada botol tersebut untuk menandai lokasi pengambilan air.

5. Kembalikan botol sampel US DH-48 ke posisi asalnya untuk mengumpulkan sampel lainnya. 
6. Pada satu lokasi/penampang, ukur kadar sedimen layang sebanyak 5 titik yaitu di tepi kiri, kiri-tengah, tengah, tengah-kanan, dan tepi kanan. Beri label untuk masing-masing posisi.

7. Ulangi langkah 2-6 untuk lokasi-lokasi lainnya.

Nantinya sampel pada US DH-48 akan diuji di laboratorium Teknik Lingkungan ITB untuk diperiksa kadar sedimen layangnya. Karena itu, penting untuk memberi label pada botol-botol yang tersedia agar informasinya tidak tertukar pada saat kadar sedimennya diuji di laboratorium.

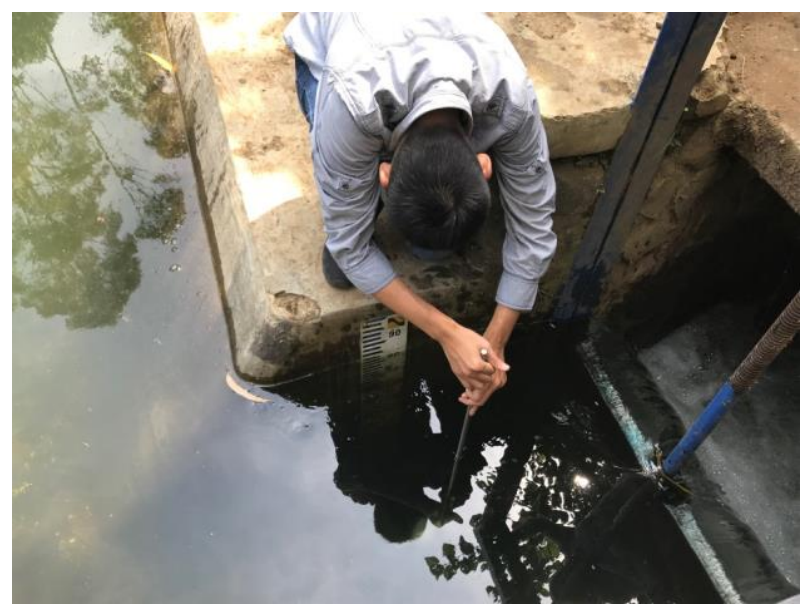

Gambar 3. Contoh pengambilan sampel sedimen layang dengan US DH-48 di Situ Cisanti

\section{HASIL DAN PEMBAHASAN}

Hasil pengukuran lapangan ditunjukkan pada Tabel 3 dan Tabel 4. Pada Tabel 3, nilai kecepatan aliran sungai didapat dari konversi rotasi currentmeter sedangkan untuk nilai kadar sedimen layang Tabel 4, nilai tersebut didapat dari pengujian laboratorium.

Tabel 3. Hasil pengukuran kecepatan di sepanjang Sungai Citarum

\begin{tabular}{|c|c|c|c|c|c|c|c|c|c|c|c|}
\hline \multirow{2}{*}{ Lokasi } & \multirow{2}{*}{$\begin{array}{l}\text { Lebar } \\
\text { Sungai } \\
\text { (m) }\end{array}$} & \multicolumn{5}{|c|}{ Kedalaman Sungai (m) } & \multicolumn{5}{|c|}{ Kecepatan Aliran (m/s) } \\
\hline & & $h_{1}$ & $\mathbf{h}_{2}$ & $\mathbf{h}_{3}$ & $h_{4}$ & $h_{5}$ & $\mathbf{v}_{1}$ & $\mathbf{v}_{2}$ & v3 & $\mathbf{v} 4$ & v5 \\
\hline Situ Cisanti & 1,14 & & & 1,01 & & & & & 0,12 & & \\
\hline Majalaya & 6,22 & 0,17 & 0,17 & 0,34 & 0,33 & 0,26 & 0,69 & 0,63 & 0,72 & 0,44 & 0,24 \\
\hline $\begin{array}{lc}\text { S. Citarum } & \text { ke } \\
\text { Waduk Cirata } & \end{array}$ & 50,67 & 5,61 & 6,82 & 5,73 & 4,62 & 0,84 & 0,09 & 0,05 & 0,09 & 0,07 & 0,04 \\
\hline $\begin{array}{l}\text { S. Citarum ke } \\
\text { Waduk Jatiluhur }\end{array}$ & 55,13 & 0,64 & 1,33 & 2,04 & 2,28 & 1,32 & 0,05 & 0,04 & 0,05 & 0,13 & 0,05 \\
\hline Muara Gembong & 67,72 & 1,83 & 3,7 & 4,12 & 5,78 & 1,47 & 0,15 & 0,30 & 0,33 & 0,30 & 0,22 \\
\hline
\end{tabular}

Catatan : titik nomor 1 adalah titik paling kiri, pandangan menghadap ke hilir. 
Tabel 4. Hasil pengukuran kadar sedimen layang di sepanjang Sungai Citarum

\begin{tabular}{|c|c|c|c|c|c|c|c|c|c|c|c|}
\hline \multirow{2}{*}{ Lokasi } & \multirow{2}{*}{$\begin{array}{c}\text { Lebar } \\
\text { Sungai } \\
\text { (m) }\end{array}$} & \multicolumn{5}{|c|}{ Kedalaman Sungai (m) } & \multicolumn{5}{|c|}{ Kadar Sedimen Layang (mg/l) } \\
\hline & & $\mathbf{h}_{1}$ & $\mathbf{h}_{2}$ & $\mathbf{h}_{3}$ & $\mathrm{~h}_{4}$ & $h_{5}$ & $\mathbf{s}_{1}$ & $\mathbf{s}_{2}$ & S3 & S4 & S5 \\
\hline Situ Cisanti & 1,14 & & & 1,01 & & & & & 14,50 & & \\
\hline Majalaya & 6,22 & 0,17 & 0,17 & 0,34 & 0,33 & 0,26 & & & & 27,00 & 45,00 \\
\hline $\begin{array}{lr}\text { S. Citarum } & \text { ke } \\
\text { Waduk Cirata } & \end{array}$ & 50,67 & 5,61 & 6,82 & 5,73 & 4,62 & 0,84 & 26,00 & 2,50 & 13,00 & 6,00 & 2,50 \\
\hline $\begin{array}{l}\text { S. Citarum ke } \\
\text { Waduk Jatiluhur }\end{array}$ & 55,13 & 0,64 & 1,33 & 2,04 & 2,28 & 1,32 & 79,00 & 90,00 & 74,00 & 87,00 & 131,00 \\
\hline Muara Gembong & 67,72 & 1,83 & 3,7 & 4,12 & 5,78 & 1,47 & 11,00 & 17,00 & 10,00 & 17,00 & 10,00 \\
\hline
\end{tabular}

Catatan : titik nomor 1 adalah titik paling kiri, pandangan menghadap ke hilir

Tabel 5. Besar flux sedimen dan volume sedimen pada lokasi pengukuran

\begin{tabular}{|c|c|c|c|c|c|c|c|c|}
\hline \multirow{2}{*}{ No } & \multirow{2}{*}{ Lokasi } & \multicolumn{5}{|c|}{ Flux sedimen per ruas $(\mathrm{g} / \mathrm{s})$} & \multirow{2}{*}{$\begin{array}{c}\text { Flux } \\
\text { Sedimen } \\
\left(\mathbf{m}^{3} / \mathbf{s}\right)\end{array}$} & \multirow{2}{*}{$\begin{array}{c}\text { Volume } \\
\text { Sedimen } \\
\text { Per Tahun } \\
\left(\mathbf{m}^{3}\right)\end{array}$} \\
\hline & & $\mathbf{f}_{\mathbf{1}}$ & $\mathbf{f}_{1}$ & $\mathbf{f}_{1}$ & $\mathbf{f}_{1}$ & $\mathbf{f}_{1}$ & & \\
\hline 1 & Situ Cisanti & & & 2,06 & & & $7,78 \cdot 10^{-7}$ & 24,52 \\
\hline 2 & Majalaya & & & & 4,92 & 3,43 & $3,15 \cdot 10^{-6}$ & 99,34 \\
\hline 3 & $\begin{array}{l}\text { S. Citarum ke Waduk } \\
\text { Cirata }\end{array}$ & 17,09 & 1,12 & 8,73 & 2,39 & 0,09 & $9,04 \cdot 10^{-5}$ & $2.851,89$ \\
\hline 4 & $\begin{array}{l}\text { S. Citarum ke Waduk } \\
\text { Jatiluhur }\end{array}$ & 3,40 & 5,31 & 9,14 & 31,26 & 10,00 & $1,98 \cdot 10^{-4}$ & $6.234,86$ \\
\hline 5 & Muara Gembong & 3,65 & 23,09 & 16,79 & 36,07 & 4,00 & $3,43 \cdot 10^{-4}$ & $10.830,83$ \\
\hline
\end{tabular}

Catatan : titik nomor 1 adalah titik paling kiri, pandangan menghadap ke hilir dan massa jenis sedimen yang dipakai adalah $2.650 \mathrm{~kg} / \mathrm{m} 3$

Analisis akan difokuskan ke Tabel 5. Di tabel ini dapat dilihat besar sedimen yang ada pada ruas sungai tersebut baik dalam bentuk flux maupun volumenya. Flux sedimen pada Tabel 5 didapat dengan mengalikan kecepatan aliran pada Tabel $\mathbf{3}$ dengan kadar sedimen layang pada Tabel $\mathbf{4}$ Volume sedimen sendiri didapat dengan mengalikan flux sedimen dengan jumlah detik dalam 1 tahun.

Hal yang paling jelas terlihat adalah jumlah sedimen yang semakin banyak dari hulu ke hilir secara bertahap :

1. Di Situ Cisanti, jumlah sedimen masih sangat sedikit karena wilayahnya yang masih berada di posisi paling atas. Karena itu, tidak banyak sedimen yang masuk ke sistem sungai.

2. Jumlah sedimen menjadi lebih banyak di hilir setelah Situ Cisanti yaitu daerah Majalaya. Jumlah sedimennya menjadi berkali-kali lebih banyak daripada di Situ 
Cisanti karena sistem sungai sudah mendapat suplai sedimen dari erosi sungai hulu maupun erosi daerah aliran sungai (DAS).

3. Kuantitas sedimen di bagian hilir Majalaya bertambah secara drastis yakni di ruas Sungai Citarum sebelum masuk ke Bendungan Cirata. Hal ini wajar karena semakin banyaknya sedimen yang tersuspensi baik dari hulu ruas ini maupun dari erosi lahan pada DAS. Selain itu, ruas ini juga mendapatkan suplai sedimen yang dilepas oleh Bendungan Saguling yang terletak di hulu Bendungan Cirata.

4. Pada pengukuran di ruas Sungai Citarum sebelum ke Waduk Jatiluhur, lokasi yang diobservasi berada sangat dekat di hilir Bendungan Cirata. Jumlah sedimen di lokasi ini relatif besar yaitu hampir 3 kali lipat dari jumlah sedimen yang masuk ke Bendungan Cirata. Sekilas, jumlah ini sangat aneh karena lokasi ini tidak banyak mendapatkan sedimen dari hulu mengingat lokasi ini berada sangat dekat di sebelah hilir Bendungan Cirata. Kemungkinan besar adalah sedimen ini berasal dari sedimen di dasar Waduk Cirata yang dilepas ke sungai.

5. Kuantitas sedimen di Muara Gembong adalah yang terbanyak di semua lokasi. Hal ini sangat wajar karena daerah hilir merupakan daerah yang paling banyak mendapatkan sedimen.

\section{KESIMPULAN DAN SARAN}

Dari kegiatan investigasi hidrometri ini, dapat disimpulkan bahwa Sungai Citarum mendapatkan banyak sedimen dari longsoran di DAS-nya. Hal ini terlihat jelas dari jumlah sedimen yang semakin banyak ke arah hilir. Bila sedimen dari longsoran DAS berjumlah sedikit, jumlah sedimen tidak akan berbeda jauh antara satu ruas dengan ruas lain. Hal ini dikarenakan sedimen yang berada di sistem aliran sungai jumlahnya tidak banyak. Karena itu, dapat disimpulkan bahwa sebagian besar sedimen yang masuk ke sistem Sungai Citarum berasal dari DAS. Hal ini juga didukung dengan fenomena perubahan tata guna lahan dari daerah perhutanan ke daerah permukiman dan industri. Hilangnya tanaman pada tanah akan menyebabkan tanah lebih mudah tererosi sehingga semakin banyak sedimen yang masuk ke dalam sungai.

Ada beberapa hal yang dapat dilakukan untuk memperbaiki hasil yang didapat dari kegiatan investigasi hidrometr dan analisisnya yaitu :

1. Investigasi sebaiknya dilakukan pada musim kemarau dan musim hujan secara rutin untuk mengetahui karakteristik hidraulik dari Sungai Citarum pada musim yang berbeda. Jumlah sedimen pada musim kemarau relatif lebih sedikit daripada musim hujan karena hujan akan menggerus tanah pada DAS dan hujan juga akan memperkuat arus sungai sehingga semakin banyak sedimen yang tersuspensi.

2. Karakteristik hidraulis aliran Sungai Citarum, baik kecepatan maupun sedimennya, sebaiknya dibandingkan dengan data yang ada dan juga dengan perhitungan teoritis. Tujuannya adalah untuk memeriksa apakah pengukuran yang dilakukan sudah mendekati fakta di lapangan. Hal-hal yang dapat dilakukan adalah dengan membandingkan data pengukuran ini dengan literatur dan penelitian yang sudah dilakukan. Perbandingan dengan data lapangan di bendungan-bendungan yang ada juga bisa dilaksanakan untuk memeriksa kuantitas sedimen eksisting.

\section{UCAPAN TERIMA KASIH}

Kami mengucapkan terima kasih kepada DPPM Untar yang telah memberi dukungan dalam bentuk dana untuk kegiatan pengabdian kepada masyarakat ini. Kami juga mengucapkan terima kasih kepada Kodam III/Siliwangi yang telah membantu kami seluruh kegiatan kami. Terakhir, 
kami mengucapkan terima kasih kepada staf dari bendungan-bendungan Saguling, Cirata, dan Jatiluhur yang telah bersedia untuk mendukung kegiatan ini.

\section{REFERENSI}

Arsyad, S. (1989). Konservasi Tanah dan Air. Bogor, Indonesia: IPB.

Badan Stardardisasi Nasional. (2008). SNI 3414-2008 Tata cara pengambilan contoh muatan sedimen melayang di sungai dengan cara integrasi kedalaman berdasarkan pembagian debit.

Ilyas, M. A. (2002). Sedimentasi dan Dampaknya pada DPS Citarum Hulu. Jurnal Teknologi

Poerbandono, A. B. (2006). Evaluasi Perubahan Perilaku Erosi Daerah Aliran Sungai Citarum Hulu dengan Pemodelan Spasial. Jurnal Infrastruktur dan Lingkungan Binaan, II(2), 21-28.

PT Indonesia Power, Unit Bisnis Pembangkit Saguling. (2008).

Sutjiningsih, D. (2012). Laporan Draft Final Pekerjaan Penanganan Sedimen di Waduk Saguling. Universitas Indonesia.

SNI 3414-2008 Tata cara pengambilan contoh muatan sedimen melayang di sungai dengan cara integrasi kedalaman berdasarkan pembagian debit 